\title{
A EDUCAÇ̃̃O FÍSICA NA ÁREA DA LINGUAGEM: O IMPACTO DA BNCC NO CURRÍCULO ESCOLAR ${ }^{1}$
}

\author{
THE PHYSICAL EDUCATION INSIDE LANGUAGE AREA: BNCC \\ IMPACT IN THE SCHOLAR CURRICULUM
}

\section{LA EDUCACIÓN FÍSICA EN LA ÁREA DEL LENGUAJE: LOS IMPACTOS DE BNCC EN EL CURRICULO ESCOLAR}

\author{
Barbara Cristina Aparecida dos Santos ${ }^{1}$ \\ Fábio Tomio Fuzii ${ }^{1}$ \\ Universidade Cruzeiro do Sul (UNICSUL), São Paulo/SP - Brasil ${ }^{1}$
}

Resumo A Educação Física escolar do século XXI traz consigo resquícios do que fora no século passado, quando chegou ao Brasil com influências europeias. Mas, visto as drásticas mudanças pelas quais a sociedade brasileira tem passado nas últimas décadas, não só no contexto social, mas também político e econômico, a Educação Física buscou questionar o seu papel enquanto parte dessa sociedade pós-moderna e refletir sobre seu campo científico, buscando subsídios nas Ciências Humanas e se apropriando dos estudos culturais e da própria área da Linguagem. Hoje, mais democrática e contextualizada com a sociedade da qual faz parte, a Educação Física vê-se em um cenário turbulento no que tange à educação escolar. Ao currículo escolar foi atribuída a Base Nacional Comum Curricular, sendo obrigatória para a Educação Básica, causando inúmeras transformações no sistema educacional e sendo seus efeitos fortemente debatidos. O respectivo artigo procura situar a Educação Física dentro do cenário acadêmico-científico, especificamente a discussão a respeito do seu objeto de estudo e discutir o impacto da BNCC na área.

Palavras-chave: Educação Física; Linguagem; Currículo.

Trabalho apresentado no V Colóquio Educação Física e Ciências Sociais em diálogo. 
Abstract In the 21st century, the Physical Education remains last century's characteristics when arrived with european influences. However, considering the drastic changes that brazilian society had been suffered in the last decades, not only in social, but also politic and economic contexts, the Physical Education questioned your function while part of this pos-modern society and think over about your scientific field, finding subsidies in Human Sciences, appropriating Cultural Studies and Language area. Nowadays, more democratic and contextualized with the society of which it is belong, the Physical Education finds itself in a turbulent scenario concerning the school education. The school curriculum has been assigned the Base Nacional Comum Curricular, it being required to basic education, causing many transformations in educational system and it effects are intensely discussed. The respective article try to situate Physical Education in the academic-scientific scenario, specifically the discussion about its object of study and to discuss the impact of BNCC in the area.

Keywords: Physical Education; Language; Curriculum.

Resumen La Educación Física escolar del siglo XXI trae consigo restos de lo que fuera en el siglo pasado, cuando llegó a Brasil con influencias europeas. Pero, visto los drásticos cambios por los que la sociedad brasileña ha pasado en las últimas décadas, no sólo en el contexto social, sino también político y económico, la Educación Física buscó cuestionar su papel como parte de esa sociedad posmoderna y reflexionar sobre su campo científico, buscando subsidios en las Ciencias Humanas y apropiarse de los estudios culturales y de la propia área del Lenguaje. Hoy, más democrática y contextualizada con la sociedad de la que forma parte, la Educación Física se ve en un escenario turbulento en lo que se refiere a la educación escolar. En el currículo escolar fue asignada la Base Nacional Común Curricular, siendo obligatoria para la Educación Básica, causando innumerables transformaciones en el sistema educativo y siendo sus efectos fuertemente debatidos. El respectivo artículo busca situar la Educación Física dentro del escenario académico-científico, específicamente la discusión sobre su objeto de estudio y discutir el impacto de la BNCC en el área.

Palabras clave: Educación Física; Lenguaje; Curriculo.

\section{INTRODUÇÃo}

Em seus primeiros passos e durante muitas décadas, a Educação Física teve o alicerce de sua área acadêmica pautada nas Ciências Biológicas. Trazida para o Brasil como métodos ginásticos, a Educação Física passou por várias transformações: pelo fenômeno da esportivização, da mecanização dos exercícios; pela fragmentação do conhecimento; pela psicobiologização; até que a área passou a se questionar enquanto ciência e finalmente lançou luz frente às Ciências Humanas e Sociais (BRACHT, 1999b).

Desse modo, a Educação Física buscou subsídios na Antropologia, Sociologia, Estudos Culturais e até na área da Linguagem. Hoje, compreendida como linguagem, a Edu-

Comunicações $\mid$ Piracicaba $\mid$ v. $26 \mid$ n. $1 \mid$ p. 327-347| jan.-abr. 2019 
cação Física escolar - que abrange os esportes, as lutas, as ginásticas, a dança, os jogos e brincadeiras e também o lazer - deixa sua antiga visão instrumental para trás e passa a levar em consideração o contexto social, cultural e político na qual se insere, fazendo reflexões sobre si própria e acerca do seu modo de ensino.

Inserida na escola, a Educação Física, além de ser influenciada pelas relações e discursos que circulam no universo escolar, é também fruto das relações de poder da sociedade mais ampla e por isso reflete em seu campo de estudo as transformações que ocorrem no contexto extraescolar.

Tendo em vista o contexto escolar e também o contexto para além dos muros da escola, é certo que a sociedade brasileira passou por drásticas mudanças políticas que acabaram refletindo no âmbito da educação. Com o mandato da presidente Dilma Roussef interrompido, o governo Temer tomou a frente política do país e aprovou novas medidas como a PEC 241 - transformada em Emenda Constitucional 95/2016 - referente ao congelamento dos gastos públicos que prevê graves cortes na área da saúde, aposentadoria e também educação; e a lei 13.415, de 2017, que reformula o Ensino Médio (BRASIL, 2016b; BRASIL, 2017).

Em consonância com essas novas medidas aprovadas, está a homologação da terceira e última versão da Base Nacional Comum Curricular (BNCC). ${ }^{2}$ Esse documento de caráter normativo reestrutura o sistema de ensino em nível nacional.

Tendo em vista essas transformações causadas pelas novas medidas implementadas no sistema educacional, a Educação Física, que tem buscado discussões para abandonar seu viés exclusivamente instrumental, e enviesada pelo caráter biológico, para ser reconhecida na área da Linguagem e subsidiada pelas Ciências Humanas e Sociais, também é parte dos processos de mudanças pelos quais a sociedade vem passando.

Assim, o respectivo artigo tem o propósito de situar a Educação Física no contexto escolar com base na implementação da Base Nacional Comum Curricular e descrever como a BNCC pode impactar o currículo escolar.

\section{CONTEXTUALizaÇão HistóRica}

Introduzida na sociedade brasileira com viés biológico e raízes europeias, a Educação Física se ancorava na educação do corpo, pautada nos métodos ginásticos militaristas e nos hábitos saudáveis, que apoiados nas concepções médicas e militares da época nortearam a área enquanto seu caráter biológico, embasada nos discursos higiênicos e eugênicos (SOARES, 2004).

A concepção curricular dominante nesses primórdios baseava-se na perspectiva higienista. Nela, a preocupação central abrangia hábitos de higiene e saúde, valorizando a disciplina, o desenvolvimento físico e moral, tomando como base fundamental a prática de exercícios físicos. A fim de concretizar seus objetivos

2 Para saber mais consulte o documento disponível em: http://basenacionalcomum.mec.gov.br/ 
formativos, a ginástica escolar deveria ser simples, de fácil execução, sem grandes despesas (NEIRA \& NUNES, 2009, p. 65).

No final do século XVIII, na Inglaterra, o panorama econômico até então estabelecido passou por grandes transformações. A chamada Revolução Industrial entrou em cena mudando os meios de produção e, por conseguinte, os pilares sociais. Em uma nova era econômica, era necessária uma remodelação política e social que atendesse às novas necessidades da sociedade. Essa transformação difundiu-se não só por toda a Europa, mas também mundialmente e foi no início do século XX que a revolução da indústria afetou e transformou diretamente o Brasil. Parafraseando Neira e Nunes (2009), a industrialização se consolidou na sociedade e a Educação Física também fez essa consolidação presente em seus discursos nas primeiras décadas do século XX.

Agora não eram mais necessários os corpos saudáveis e fortes preparados para serviços duros e militares, por intermédio do taylorismo e do fordismo - concepções provindas que propuseram novos meios para a produção industrial - a ideia de corpo mudou. Era preciso um contingente de proletários capazes de passarem o dia todo a realizar movimentos repetitivos e fragmentados, ou seja, aquele trabalhador autônomo que produzia pouco em um dia, mas detinha conhecimento acerca de todas as fases de sua produção fora descartado. No mundo industrializado, cada trabalhador passou a conhecer apenas uma pequena parcela do todo de produção. Por conseguinte, os novos modos econômicos refletiram em toda a sociedade, até nas propostas de ensino escolar: nascera o tecnicismo.

Naquele contexto, os docentes preocupavam-se mais em garantir o controle e a obediência ao alunado, enquanto os discentes elaboravam estratégias para sobreviver aos ditames educacionais: memorizavam, caprichavam nas aparências dos exercícios, mantinham-se em filas etc. (NEIRA \& NUNES, 2009, p. 72).

Então, os métodos ginásticos foram substituídos por exercícios mecânicos e repetitivos, que representando a fragmentação do todo, induziam à meritocracia e à competitividade. Denominou-se o fenômeno de esportivização da Educação Física. "A pedagogia da EF incorporou, sem necessidade de mudar seus princípios fundamentais, essa nova técnica corporal, o esporte" (BRACHT, 1999a). Isso significa que, mesmo a Educação Física tendo passado pela esportivização, a área continuou com seu viés biológico, sem levar em consideração a ancoragem social das práticas corporais, e até mesmo o contexto sociopolítico.

Denota-se claramente como a Educação Física se tornou uma peça fundamental das estratégias de intervenção sobre o corpo, ou seja, o esforço na disciplinarização, no controle dos indivíduos, tendo no corpo um espaço de investimento de poder. Tanto nos métodos ginásticos quanto em sua fase de esportivização, a Educação Física reconhecia o corpo como algo biológico, um alvo de intervenção para manutenção e reprodução da lógica da sociedade capitalista (SOARES, 2004).

Apoiando-se em conceitos psicobiológicos, a Educação Física marcou sua especificidade na escola como sendo uma disciplina para desenvolver aspectos motores, biológicos 
e psicológicos, entretanto, sua prática não conseguiu superar uma visão instrumental de Educação Física. A partir da década de 1980, a Educação Física criticou sua função de buscar talentos esportivos e começou a se nutrir de conhecimentos de outras áreas para a elaboração de seus currículos (SOARES et al., 1992; KUNZ, 1998; BETTI \& ZULIANI, 2002; NEIRA \& NUNES, 2008).

Nesse itinerário de empenho por uma identidade em consonância com a função social da escola, a Educação Física também buscou subsídios teóricos nas Ciências Humanas e Sociais, principalmente na Pedagogia, para pensar a sua prática pedagógica. "Essa relação ganhou corpo especificamente no âmbito escolar com a aproximação das análises críticas a respeito da função social da educação e, particularmente, da educação física" (NEIRA, 2007, p. 2-3).

Fugindo dos parâmetros mecanicistas, essa linha reflexiva da área procurou compreender o movimento humano não como um produto de sínteses metabólicas ou como um conjunto de alavancas, mas como uma ação que está carregada de gestualidade.

A partir de então, no entendimento de Santin (1987) são quatro as concepções definidas sobre o movimento humano: a primeira diz respeito à biomecânica, nela o movimento humano busca sua eficiência motora regido pelas leis da física mecânica, uma vez que o homem é compreendido como uma máquina viva; a segunda concepção se baseia na fisiologia do exercício e entende o movimento humano como resultado da produção de energia pautada nos conceitos dos mecanismos metabólicos do organismo; a terceira ainda se encontra fortemente presente em determinados currículos da Educação Física, pois essa concepção de movimento humano se concentra na aprendizagem das habilidades motoras básicas e se estende à aprendizagem das habilidades motoras específicas enquanto objetivo da área; a quarta e última tem como objeto de estudo da Educação Física a cultura corporal, já que ao se movimentar o corpo carrega significados construídos culturalmente por indivíduos sociais que se movimentam intencionalmente.

Finalmente, o corpo pode também ser entendido como forma de expressão. $\mathrm{O}$ que o torna portador de significados e meio privilegiado para expressar sentimentos, emoções e toda produção cultural de um determinado grupo social. Nesse sentido, o movimento humano é uma forma de linguagem e mais facilmente traduzida pelo termo "gesto". O gesto, por sua vez, é entendido como um movimento intencional significativo do ponto de vista sociocultural, dado que se constrói na relação sujeito-cultura e permite a comunicação entre os membros de um determinado grupo (NEIRA \& NUNES, 2007, p. 3).

Para esse entendimento, faz-se necessário ressaltar as contribuições de um livro intitulado "Metodologia do ensino de Educação Física", publicado em 1992, por um grupo de professores - Carmen Lúcia Soares, Celi Taffarel, Elizabeth Varjal, Lino Castellani Filho, Micheli Ortega Escobar e Valter Bracht - que definiu a cultura corporal como objeto de conhecimento da Educação Física.

Sendo assim, a cultura corporal passou a ser alvo de atenção da Educação Física, que com um novo olhar para o seu campo científico, buscou uma nova compreensão acerca de 
suas práticas pedagógicas, não mais enviesada pelo caráter biológico, mas sim pautada na constituição da cultura dos sujeitos que é expressa por suas práticas de significação. Por conseguinte, a Educação Física ganhou uma nova inserção nos currículos escolares: o pertencimento na área da linguagem.

\section{O CONCEITO DE LINGUAGEM E A NOÇão DE CULTURA}

Para alguns autores, como afirmam Santos, Marcon e Trentin (2012), considerar a Educação Física como linguagem não é uma tarefa simples, já que essa compreensão envolve conceitos inéditos e pouco transparentes. Sendo assim, para compreendermos a Educação Física como linguagem, lançaremos luz sobre as concepções dos diferentes estudiosos da área da Linguagem para primeiro definirmos esse complexo fenômeno.

Segundo Fiorin (2015), as linguagens podem ser definidas como sistemas de signos usados para a comunicação, sejam linguagens verbais, escritas, visuais como as pinturas ou sonoras como a música. Para o autor, a linguagem não nos permite somente nomear objetos, mas é justamente a possibilidade de transformar o mundo real, é a troca de experiências, de ideias, de informações, a linguagem é veículo da comunicação social.

Para Hjelmslev, é graças à linguagem que o homem vai modelar seus pensamentos, sua vida, suas emoções e até seus desejos, pois o homem não pode se separar da linguagem, uma vez que essa o segue em todos os seus atos, já que é "a base última e mais profunda da sociedade humana" (HJELMSLEV, 2006, p. 1).

O desenvolvimento da linguagem está tão inextricavelmente ligado ao da personalidade de cada indivíduo, da terra, da nação, da humanidade, da própria vida, que é possível indagar-se se ela não passa de um simples reflexo ou se ela não é tudo isso: a própria fonte do desenvolvimento dessas coisas (p. 2).

A sociedade apresenta diferentes modos de vida adotados pelos grupos humanos que a compõem, a história de um povo, suas crenças, anseios, vestimentas e também suas práticas corporais, que são formas de linguagem, estão carregadas de significados expressos na interação com o outro.

Dada a constatação de que não há linguagem sem sociedade e não há sociedade sem grupos culturais, uma vez que "linguagem e sociedade estão ligadas entre si de modo inquestionável, mais do que isso, podemos afirmar que essa relação é a base da constituição do ser humano" (ALKIMIN, 2006, p. 23) é possível afirmar que a linguagem, a sociedade e a cultura são componentes inextricáveis ao homem e relacionados entre si.

Assim como não há sociedade sem linguagem, não há sociedade sem comunicação. Tudo o que se produz como linguagem ocorre em sociedade, para ser comunicado, e, como tal, constitui uma realidade material que se relaciona com o que lhe é exterior, com o que existe independentemente da linguagem [...] a linguagem é relativamente autônoma; como expressão de emoções, ideias, propósitos, no entanto, ela é orientada pela visão de mundo, pelas injunções da realidade social, histórica e cultural de seu falante (FIORIN, 2015, p. 11). 
Desse modo, o fenômeno da linguagem não pode ser compreendido sem levar em consideração a compreensão de cultura, pois esta interfere diretamente na visão de mundo e nas formas de relação dos sujeitos. O conceito de cultura ganha novas possibilidades de significado na medida em que:

\begin{abstract}
Cultura transmuta-se de um conceito impregnado de distinção, hierarquia e elitismos segregacionistas para um outro eixo de significados em que se abre um amplo leque de sentidos cambiantes e versáteis. Cultura deixa, gradativamente, de ser domínio exclusivo da erudição, da tradição literária e artística, de padrões estéticos elitizados e passa a contemplar, também, o gosto das multidões (COSTA, SILVEIRA, SOMMER. 2003, p. 36).
\end{abstract}

Nesse sentido, a cultura não é um fenômeno homogêneo, as culturas dos diversos grupos sociais são diferentes e apresentam diferentes representações e significados, para cada grupo da qual faz parte, a cultura ganha diferentes interpretações. É preciso, antes de tudo, compreender o fenômeno da cultura como heterogêneo.

Portanto, cada sociedade, cada grupo social distinto apresentará uma repercus-
são corporal igualmente distinta. Isso faz com que cada cultura produza homens
com hábitos corporais, com tipo de movimentos característicos dessa cultura.
É como se uma marca fosse impressa pelo modo como se vive, em outras pala-
vras, pela cultura (VAZ, 2010, p. 102).

Como já mencionado, a Educação Física abarca o conceito de cultura ao elaborar o termo cultura corporal. Deste ponto em diante, destaca-se a noção de cultura para a área.

Para Daolio (2004), apoiado nos estudos antropológicos de Clifford Geertz, para ampliar os horizontes da Educação Física, leva em consideração a dimensão cultural simbólica dos sujeitos e assim o homem passa a ser compreendido como ser cultural, contínuo construtor de cultura, e esta, por sua vez, é relacionada aos aspectos corporais.

Ou seja, para Daolio (2004), não pode haver uma visão de homem como ser estritamente biológico, pois o que lhe dá singularidade é a sua ação social que compartilha signos e significados para a construção de diferentes padrões culturais.

Por exemplo, o voleibol é constituído por diversos símbolos, porém podem ser atribuídos significados diferentes. Sendo assim, um grupo de idosos que praticam voleibol por socialização com os amigos ou um tempo de lazer atribui significados diferentes à prática para aqueles profissionais que têm na disputa esportiva a caracterização do seu trabalho.

Essa interpretação rompe com qualquer possibilidade de hereditariedade cultural e afirma que a cultura é preservada, transmitida, reproduzida pelos diversos grupos sociais.

Portanto, o patrimônio cultural e histórico da Educação Física é subsidiado pela eficácia simbólica de suas práticas corporais, quando o aluno se apropria de uma prática corporal, essa aprendizagem permite a aquisição de um universo de significados culturais que são construídos e legitimados na cultura a que pertencem, e se passa a aceitar e a compreender certos valores específicos daquela determinada prática (VELOZO, 2010). 
Entretanto, é com Soares et al. (1992) - com o mesmo livro supracitado "Metodologia do ensino de Educação Física" - que o termo cultura corporal de movimento ganha destaque na área, sendo reconhecida como objeto de conhecimento. Além disso, insere a Educação Física na área da linguagem: A Educação Física é uma disciplina que trata, pedagogicamente na escola, do
conhecimento de uma área aqui denominada de cultura corporal. Ela será con-
figurada com temas ou formas de atividades, particularmente corporais [...]:
jogo, esporte, ginástica, dança ou outras, que constituirão seu conteúdo. O es-
tudo desse conhecimento visa apreender a expressão corporal como linguagem
(SOARES et al., 1992, p. 61).

A Educação Física compreendida como linguagem rompe com as barreiras impostas pelo histórico da área pautado unicamente no caráter biológico e passa então a dar um entendimento mais abrangente sobre o corpo.

Na relação entre Educação Física e Linguagem, o corpo, além de apresentar as questões biológicas e fisiológicas, é um texto a ser lido e interpretado, pois é também no corpo que o ser humano transparece sua identidade, sua cultura, suas marcas históricas, suas crenças.

Com as práticas corporais não é diferente, a partir do momento em que se desconstrói o daltonismo cultural, as múltiplas culturas passam a ser encaradas não como melhores ou piores, mas como diferentes. E desse modo, os corpos e os gestos manifestados por esses corpos passam a ser interpretados e ganham diferentes significados, com base na cultura e na sociedade em que estão inseridos.

O corpo em movimento não diz respeito somente ao seu caráter biológico, nem tampouco pode significar o movimento como meio e único fim do ato de movimentar-se, pois ao dançar, lutar, jogar, praticar esportes, praticar ginástica, "essas práticas corporais ou formas de manifestações culturais são denominadas cultura corporal, cultura corporal de movimento ou cultura de movimento" (NEIRA, 2007, p. 5) e estão carregadas de significados, além do que, o corpo que é também uma construção cultural inserido na sociedade, manifesta a sua própria linguagem carregada de intenções.

Ao se movimentar, homens e mulheres expressam intencionalidades, comunicam e veiculam modos de ser, pensar e agir característicos, ou seja, culturalmente impressos em seus corpos. Qualquer corpo, portanto, é um suporte textual, nele se inscrevem a história e trajetória dos homens e da cultura (NEIRA \& NUNES, 2007, p. 6).

Desse modo, a linguagem corporal é carregada de significados culturais construídos socialmente, que permitem a compreensão de todo e qualquer movimento não apenas como ato mecânico, mas sim como "texto" a ser lido, ancorado no grupo ao qual esse corpo pertence.

Segundo Neira (2007), os textos produzidos pela linguagem corporal são formas de se comunicar com o mundo, e portanto, cada texto imprime uma linguagem específica a ser interpretada. "Ao jogar, dançar e correr, as crianças comunicam e transformam em linguagem o movimento” (p. 11).

Comunicações | Piracicaba | v. $26 \mid$ n. $1 \mid$ p. 327-347| jan.-abr. 2019 
Foi por meio dessas concepções de movimento, objeto da Educação Física, compreensão da sociedade, linguagem e cultura que a área passou a fazer parte da linguagem em propostas oficiais de currículos da educação básica (SÃO PAULO, 2007; JUNDIAÍ, 2016; SÃO PAULO, 2016; SÃO PAULO, 2017; SÃO PAULO, 2018).

Não se pode deixar de mencionar que o conceito de cultura e, por conseguinte, de linguagem também sofrem influências dos Estudos Culturais, pois além de rechaçar qualquer concepção elitista de cultura, realçarão o aspecto político no entendimento de cultura.

Surgindo em meio a movimentos de contestação de grupos desprivilegiados da sociedade pelo impedimento da leitura da realidade pelos seus saberes em detrimento de uma visão elitista, os Estudos Culturais se engajam nas propostas de democratização das relações de poder e nas transformações sociais (NEIRA \& NUNES, 2009).

Para Wortmann e Veiga Neto (2001), os Estudos Culturais, imbuídos na Ciência e Educação, não buscam definir seu objeto de estudo com concepções bem demarcadas, mas sim, situá-lo como campo de conhecimentos e práticas que se relacionam com outros campos de estudos, examinando as práticas culturais e suas possibilidades de articulação, conhecimento e poder.

Nesse sentido, os Estudos Culturais buscam a multidisciplinariedade, uma vez que estudam os fenômenos sociais e culturais, trazendo para o diálogo diferentes questões de identidade, política, poder, alta e baixa cultura, valorização e desvalorização (ORTIZ, 2004).

Imbuídos de uma conotação política, os Estudos Culturais entenderão que as sociedades capitalistas são lugares que produzem desigualdades no que se refere à etnia, sexualidade, classes, gerações, entre outros (HALL, 1997).

Assim existe uma disputa para fazer valer a interpretação das práticas culturais por diversos grupos. Por exemplo, no entendimento de "alta cultura" - aqueles considerados cultos - e "baixa cultura" - os sem cultura, incultos, que precisam ser inculcados da cultura verdadeira - são julgamentos estabelecidos pelos representantes da "alta cultura", ou seja, foram os grupos com maior poder de legitimar determinada visão de grupo que se impuseram sobre aqueles com menor força (COSTA, SILVEIRA \& SOMMER, 2003; NEIRA \& NUNES, 2009).

Por isso que Neira e Nunes (2009) afirmam que a cultura se configura como um terreno de confronto entre diversas práticas de significação que buscam validação e reconhecimento.

Utilizando as contribuições de Hall (1997), que aponta a relação entre cultura e poder e uma disputa simbólica e discursiva na economia, na regulação, na produção de identidades e representações, entre outras práticas sociais que é possível apontar que:

É na esfera cultural que se dá a luta pela significação, na qual os grupos subordinados procuram fazer frente à imposição de significados que sustentam os interesses dos grupos mais poderosos. Nesse sentido, os textos culturais são o próprio local onde o significado é negociado e fixado (COSTA, SILVEIRA \& SOMMER, 2003, p. 38).

Por meio dos Estudos Culturais, podemos olhar para a Educação Física e reconhecer um campo de constante disputa de significação e identidade para ora um sujeito saudável, 
ora um sujeito esportivamente habilidoso e ora um sujeito capaz de reconhecer a diversidade cultural de movimento.

Sendo assim, olhar para os currículos de Educação Física e as propostas curriculares oficiais da área e da educação denota que houve um intenso processo de disputa para legitimar determinada visão de Educação Física, Educação e das identidades que se querem produzir para um tipo de sociedade. Olhar para o currículo também é uma questão de poder. Assim, privilegiar determinado tipo de conhecimento e não outro é uma operação de poder, ou seja, assumir/decidir uma identidade ou uma subjetividade entre as múltiplas possibilidades acaba configurando um exercício de poder. Portanto, aqueles que detêm o poder sobre a construção dos currículos, afirmam sua autoridade por meio deles (SILVA, 2011; YOUNG, 2014).

\section{A TEORIZAÇÃo CURRICULAR}

A compreensão do currículo pode nos levar a um entendimento de algo estático, como uma ideia de uma cultura educacional (fixa, estável, herdada) que pretende proporcionar um conhecimento (como um fato e informação) legítimo para aqueles aprendizes em formação. Nessa linha, há também uma interpretação de currículo como um documento legal que descreve o processo de ensino, uma ordenação de disciplinas e recomendações didáticas (SILVA, 2011).

Entretanto, ao abordar o currículo é necessário compreender que se trata de um artefato cultural, ou seja, algo produzido pelo homem, influenciado pelo contexto histórico-social no momento de sua elaboração. Ou seja, não se trata de um objeto neutro, que apenas retrata uma seleção dos melhores conhecimentos para ser abordado na escola.

Isso fica claro ao perceber que os estudos curriculares ganharam força no início do século XX, no contexto de industrialização e urbanização, relacionado ao intenso processo de massificação da escolarização. A partir de então, começou-se a pensar em formatar o currículo para garantir a formação de um sujeito desejável às novas exigências sociais. A intenção era introjetar identidades particulares nos estudantes que passavam pela experiência curricular (NEIRA \& NUNES, 2009).

Por essa ideia que Silva (2011) afirma que o currículo é um documento de identidade e que produz subjetividades durante o processo educacional para nos tornar o que somos. Por isso que o autor esclarece que o currículo está envolvido por questões de poder, afinal selecionar os conhecimentos e formatar a experiência curricular para produção de determinados sujeitos é uma questão de poder, pois se privilegia determinado tipo de conhecimento e não outro e assume uma identidade/subjetividade a ser alcançada e descarta outras múltiplas possibilidades.

Para Saviani (2016), o conceito de currículo vai além das disciplinas que compõem um curso, em se tratando da prática pedagógica, o currículo é a própria escola em seu funcionamento, o que inclui o saber sistematizado, mas além disso, a forma de transmissão e de assimilação dos saberes e até os próprios saberes selecionados. 
Os currículos interferem na construção das identidades dos sujeitos presentes no âmbito escolar - alunos, professores e os demais profissionais - pois são veiculadas visões de mundo, de sociedade, posições ideológicas, que marcam os sujeitos ali presentes (SILVA, 2011).

Neira e Nunes (2009), com um olhar advindo dos Estudos Culturais, apontam que o currículo é um campo de luta em torno da significação e da identidade, ou seja, diferentes grupos tentam estabelecer no currículo sua hegemonia e projetar identidades desejáveis. Veja que essa análise focaliza a questão do poder.

Em vista disso, é possível indagar quem tem poder para definir quais os conhecimentos que devem perpassar um currículo. Afinal, a escolha de determinado conhecimento é a negação de outro. Ou que identidade se deseja projetar nos sujeitos por meio da experiência curricular? Pois assumir determinada identidade é também negar a validade de outras identidades.

Com esse olhar do currículo enquanto um território de disputas por legitimação de determinados grupos, podemos ver o constante debate não só pelos teóricos da área, mas pela sociedade civil e pelo setor empresarial em torno da validação dos conhecimentos e práticas dentro das escolas, nos jornais, mídias sociais e na construção de propostas oficiais de ensino. Esse foi o caso da construção da Base Nacional Comum³ (VERDE, 2015).

É possível então afirmar que o currículo, como centro de disputas, veicula ideologias, visões de mundo, forma cidadãos e à medida que ensina certos conteúdos, deixa de ensinar outros. Desse modo, vale refletir que o currículo da Base Nacional Comum Curricular, obrigatório em todo o país, também é composto por essas lutas dos diversos grupos que tentam legitimar suas visões de mundo e pelos diferentes setores da sociedade inseridos no meio educacional.

\section{EduCAÇão FísicA No ÂMBITo LEGAL}

Para compreendermos os motivos pelos quais se aprovou legalmente a construção da Base Nacional Comum Curricular e sua obrigatoriedade nos currículos escolares, é antes necessário entender como a Educação Física se insere no sistema educacional brasileiro, bem como, entender os marcos legais que levaram à implementação da BNCC.

3 Essas disputas por legitimação da visão de diferentes grupos fizeram parte da construção da BNCC. Em 6 de março de 2018, ocorreu uma discussão nacional nomeada como "Dia D" e contou com a participação das secretarias municipais e estaduais, bem como, professores e integrantes da equipe escolar. Porém, isso só serviu para dar um ar democrático ao documento, pois se sabe que a grande influência do BNCC parte de grupos empresariais. Existe um movimento chamado "Movimento pela Base Nacional Comum", que conta com o apoio de instituições privadas e ONGs como a Fundação Lemann, Fundação Roberto Marinho, Instituto Ayrton Senna, Instituto Natura, Instituto Unibanco, Itaú BBA, entre outras. Ver em: http://movimentopelabase.org.br/quem-somos/ 
É pela Lei 9.131, novembro de 1995, e com base nos preceitos legais do artigo $210,{ }^{4}$ da Constituição Federal de 1988, que o Conselho Nacional de Educação (CNE) foi criado. O Conselho Nacional de Educação, bem como, a LDB 9.394 de 1996, determinados pela Constituição Federal, já apontavam a necessidade de Diretrizes Curriculares Nacionais para nortear os currículos das escolas.

\begin{abstract}
Desse modo, através dos encaminhamentos da Constituição Federal, da LDB e da criação do CNE, os currículos e conteúdos mínimos propostos pelos Parâmetros Curriculares Nacionais, a organização do trabalho educativo nas escolas, teriam seu referencial mediado pelas diretrizes curriculares (LILIAN, 2007, p. 16).
\end{abstract}

No que tange o âmbito legal, a Educação Física deu seu primeiro passo para ser entendida como uma disciplina escolar, que possui uma proposta pedagógica e que deve ser articulada com o Projeto Político Pedagógico com a Lei de Diretrizes e Bases (LDB) nº 9.394, de 1996 (BRASIL, 1996). Nesse momento, a área não pode mais ser compreendida enquanto mera atividade e passou a ser encarada como componente curricular, se igualando às demais disciplinas. "A educação física, integrada à proposta pedagógica da escola, é componente curricular da Educação Básica, ajustando-se às faixas etárias e às condições da população escolar, sendo facultativa nos cursos noturnos" (BRASIL, 1996).

"Retira-se, com essa redação, a camisa de força que a aprisionava nos limites próprios ao famigerado eixo paradigmático da aptidão física, à medida que a vinculava tão somente à busca do desenvolvimento físico do aluno" (CASTELLANI FILHO, 1998, p. 18).

Iniciando seus primeiros passos para ser desatrelada da aptidão física, foi no documento oficial dos Parâmetros Curriculares Nacionais (PCN), (BRASIL, 1998), que a Educação Física foi reconhecida pela primeira vez como parte da área das linguagens e códigos, que até então abrangia somente as disciplinas de Língua Portuguesa, Língua Estrangeira, Artes e Informática.

De acordo com Darido e Ladeira (2003), a proposta do documento supracitado era de prover formas de atuação para que os profissionais de Educação Física promovessem o desenvolvimento dos alunos em sua totalidade. Entretanto, apesar de representar um avanço para a Educação Física escolar, o documento foi fortemente criticado pela escassa democracia no momento de sua constituição e além disso, a inserção da Educação Física no componente curricular das linguagens e códigos foi apenas superficialmente discutido e de forma acrítica, por isso vimos um processo de questionamento de sua proposta, tanto em termos legais, quanto em relação às mudanças efetivas na prática pedagógica dos professores.

Recentemente, a construção da Base Nacional Comum Curricular, assim como os documentos anteriores a ela, fizeram novas atribuições para o campo da Educação Física e por isso contamos com uma análise mais atenta para esse documento.

4 Ver artigo 210: http://www.senado.leg.br/atividade/const/con1988/con1988_12.07.2016/ art 210.asp 


\section{UM OLHAR CRÍTICO SOBRE A BNCC}

A Constituição Federal de 1988, em seu artigo 22, Inciso XXIV, delega à União o poder de legislar acerca das diretrizes e bases da educação nacional, visto isso, a Lei de Diretrizes e Bases da Educação Nacional (BRASIL, 1996) já previa a construção de uma base comum para a educação desde o ano de sua promulgação.

A Base Nacional Comum Curricular é um documento de caráter normativo, cuja constituição teoricamente prevê equidade, pluralidade, superação de barreiras no ensino educacional brasileiro, bem como, um lugar-comum para que todos os estudantes em nível nacional tenham garantidos os seus direitos de acesso, políticas de permanência e o desenvolvimento de suas competências e habilidades durante as etapas da Educação Básica.

A BNCC teve sua terceira e última versão homologada, em 2017, pelo Conselho Nacional de Educação (CNE) e passa a ser obrigatória para a elaboração dos currículos escolares de todo o país. Mas, antes dessa versão final ser elaborada, o documento passou por duas versões anteriores, que tiveram diferentes características nos processos de construção e contaram com diferentes críticas.

A primeira versão da BNCC recebeu fortes críticas tanto de conservadores, que compreendiam o texto como aquém do ideal para transmissão de conhecimentos, quanto de progressistas, que esperavam um maior engajamento político do documento. A segunda versão do documento, publicada em abril de 2016, se mostrava mais democrática, não só nas etapas de construção, já que contou com milhões de sugestões e contribuições da sociedade brasileira pelo portal da BNCC e por outros veículos de comunicação, mas também nos ideais e descrições realizados por todo o documento (NEIRA \& JÚNIOR, 2016).

A segunda versão da BNCC colocava em questão os princípios éticos, políticos e estéticos, se mostrava em prol das discussões sobre diversidade, pluralidade, questão de gênero, classe; além disso, revelava ser dever da educação formar sujeitos para uma sociedade menos injusta, menos desigual, mais inclusiva e que reconhece as diferenças. Já a versão final homologada, além de fazer apenas uma alusão às questões supracitadas, insere o desenvolvimento de competências no lugar dos direitos de aprendizagem e desenvolvimento (NEIRA, 2017).

Além disso, a versão final homologada da Base Nacional Comum Curricular contém um enfoque cognitivista e instrumental (de modo diferente do que propõe a inserção da Educação Física na área da Linguagem), o que causa um retrocesso não só para a área da Educação Física, mas também para a educação em geral, já que há "o esvaziamento crítico e democratizante para dar lugar a uma formação instrumental alinhada aos ditames do mercado" (NEIRA, 2017, p. 5).

De acordo com Marsiglia et al. (2017), foi a partir do golpe jurídico-midiático-parlamentar de Estado que ocorreu uma significativa mudança nos cargos ocupados pelos responsáveis pela construção da Base Nacional Comum Curricular, e essa mudança implicou graves consequências na elaboração do documento. Com novos sujeitos envolvidos no âmbito educacional, as reformas educacionais passaram a obedecer aos ditames do setor empresarial, o que acarretou na: 
[...] ausência de referência em relação aos conteúdos científicos, artísticos e filosóficos, e a ênfase em métodos, procedimentos, competências e habilidades voltadas para a adaptação do indivíduo aos interesses do grande capital. Expressando a hegemonia da classe empresarial no processo de elaboração do documento (MARSIGLIA et al., 2017, p. 109).

O artigo 26 da LDB 9.394/96 prevê uma base nacional comum para o ensino escolar, contendo também uma parte diversificada a ser elaborada. Essa parte diversificada é reforçada pelo Ministério da Educação na resolução n ${ }^{0}$. 7, de 14 de dezembro de $2010,{ }^{5}$ que fixa Diretrizes Curriculares Nacionais para o Ensino Fundamental, "não é claro, porém, a que instância cabe a eleição dos conteúdos curriculares a partir das diretrizes propostas pela União através da LDB” (LIMA VERDE, 2015, p. 81).

Assim, os conteúdos curriculares e essa parte diversificada já prevista na LDB ficam à mercê da iniciativa privada, como é o exemplo do movimento Todos pela Educação (TPE), ${ }^{6}$ que apesar de se afirmar como apartidário e plural, é mantido por grandes empresas privadas e estas acabam fazendo parte do Fórum Nacional de Educação.

É necessário ressaltar que o Fórum Nacional de Educação, criado pela Portaria MEC $n^{\circ}$. 1.407/10, legitimado pelo Plano Nacional de Educação (Lei $n^{\circ}$. 13.005/14), é formado por 44 entidades representantes da sociedade civil e do poder público, sendo algumas de suas cadeiras ocupadas por membros do Movimento Todos pela Educação (LIMA VERDE, 2015, p. 86).

Em sua versão final promulgada em 2017, a Base Nacional Comum Curricular passa a estipular competências para os estudantes desenvolverem no decorrer dos nove anos do ensino fundamental.

Ao longo da Educação Básica, as aprendizagens essenciais definidas na BNCC devem concorrer para assegurar aos estudantes o desenvolvimento de dez competências gerais, que consubstanciam, no âmbito pedagógico, os direitos de aprendizagem e desenvolvimento (BRASIL, 2017).

A educação deve, de acordo com a Constituição Federal e LDB, desenvolver a pessoa em sentido pleno, desde o exercício da cidadania, aprimoramento como ser humano, até o preparo para o trabalho. Mas essa finalidade do sistema educacional não poderá se concretizar:

Com currículos que pretendam conferir competências para a realização das tarefas de certo modo mecânicas e corriqueiras demandadas pela estrutura ocupacional concentrando-se na questão da qualificação profissional e secundarizando o pleno desenvolvimento da pessoa e o preparo para o exercício da cidadania, tal como se evidencia na proposta divulgada pelo MEC sobre a base nacional comum curricular (SAVIANI, 2016, p. 82).

\footnotetext{
5 Resolução $n^{\circ} .7$, de 14 de dezembro de 2010, fixa Diretrizes Curriculares Nacionais para o Ensino Fundamental de 9 (nove) anos. Vide: http://portal.mec.gov.br/dmdocuments/rceb007_10.pdf

6 Empresas mantenedoras do TPE, 2018. Vide https://www.todospelaeducacao.org.br/pag/o-todos/\#bloco_76
} 
Como já descrito, apesar de a promulgação da Base Nacional Comum Curricular estar prevista e já ser exigida na Lei de Diretrizes e Bases da Educação Nacional, nas Diretrizes Curriculares Nacional e no próprio Plano Nacional de Educação, o modo como se deu a transição da segunda para a terceira versão do documento representou um retrocesso para a educação. E essa transição da segunda para a terceira versão do documento da BNCC foi reflexo dos processos políticos ocorridos na sociedade mais ampla. Com a mudança do cargo à presidência, muitos dos sujeitos que participaram da primeira e segunda versão da BNCC também foram substituídos, o que acarretou na influência do setor empresarial na composição final do documento.

Especificamente para a Educação Física, conforme também alertou Neira (2017), não há na versão final homologada os seguintes preceitos que constavam na segunda versão do documento:

Compreender e valorizar os diferentes sentidos e significados das brincadeiras e jogos populares do contexto comunitário e regional, da cultura indígena e da afro-brasileira (p. 248).

Contribuir no enfrentamento de situações de injustiça e preconceito, geradas e/ ou presentes no contexto da prática esportiva, com ênfase nas problemáticas de gênero e na produção de alternativas democráticas para sua superação (p. 392). Enfrentar, com autonomia, situações de injustiça e preconceito geradas e/ou presentes no contexto da prática esportiva e produzir alternativas para sua superação, com especial atenção nas questões étnico-raciais e indígenas (BRASIL, 2016, p. 398 - grifos do autor).

E, já na terceira versão da $\mathrm{BNCC}$, as práticas corporais são definidas com elementos comuns que retomam os antigos ideais de Educação Física, já descritos no contexto histórico da área, com base nos métodos higienistas e que também retomam conceitos cognitivistas:

Há três elementos fundamentais comuns às práticas corporais: movimento corporal como elemento essencial; organização interna (de maior ou menor grau), pautada por uma lógica específica; e produto cultural vinculado com o lazer/ entretenimento e/ ou o cuidado com o corpo e saúde (BRASIL, 2017, p. 211).

$\mathrm{O}$ apagamento dos preceitos já citados e que faziam parte da $\mathrm{BNCC}$ em processo de construção, se somados às concepções acríticas da terceira versão da Base Nacional Comum Curricular e que retomam o caráter higienista e cognitivista da Educação Física, representam não só um extremo retrocesso para a área, mas também podem significar um perigo para o próprio campo da Educação Física, como também um distanciamento da construção da área enquanto Linguagem. 


\section{CONSIDERaÇões FINAIS}

É fato que a área da Educação Física se reformulou com o passar do tempo, seus objetivos anteriormente pautados na disciplinarização dos corpos e nos hábitos de saúde deram lugar à cultura corporal. Então, conforme é perceptível nos documentos legais (PCN e BNCC) e em propostas oficiais de currículos de Educação Básica - citando como exemplo os currículos da cidade de São Paulo já mencionados - a Educação Física passou a questionar seu campo teórico e buscou refletir sobre a sociedade mais ampla com base nos Estudos Culturais, nas Ciências Humanas, ganhando sua inserção no componente das Linguagens (BRASIL, 1998; BRASIL, 2017; SÃO PAULO, 2007; SÃO PAULO, 2016; SÃO PAULO, 2017; SÃO PAULO, 2018).

Agora contextualizada com as questões políticas, econômicas e sociais da sociedade brasileira, a Educação Física procura refletir sobre os processos de transformação do âmbito da educação escolar, o que representa um grande avanço para a área.

Diante de tudo o que foi dito sobre teorização curricular, conclui-se que ter um documento como a Base Nacional Comum Curricular sendo obrigatória em todo o país, com a força de orientar os currículos de todas as escolas brasileiras, partindo do princípio de eleger os mesmos conteúdos para grupos muito distintos, não condiz com a sociedade multifacetada, tampouco com a pluralidade das culturas existentes em todo o território nacional.

Além disso, no que diz respeito ao processo de construção da BNCC, é possível notar um significativo rompimento entre a segunda e a terceira versão final publicada. A segunda versão se mostrava muito mais aberta ao diálogo, acessível aos profissionais da educação e à comunidade; também continha um teor mais democrático no sentido de formação de cidadãos críticos e prontos para o exercício da cidadania. Enquanto que o documento final publicado ocasionou o apagamento de muitas dessas contribuições e também retrocedeu a $\mathrm{BNCC}$ aos preceitos cognitivistas e instrumentais.

Outra observação facilmente realizada é a de que a versão final publicada da Base Nacional Comum Curricular, apesar de teoricamente se dizer plural e afirmar a busca pela equidade e superação das injustiças sociais, é um documento totalmente voltado para as instituições privadas, para o desenvolvimento de competências, para o setor empresarial, o que além de distanciar os alunos de uma formação mais democrática, acaba por representar um retrocesso para a educação.

Em suma, é inegável que a Base Nacional Comum Curricular irá impactar os currículos escolares, e com base no que foi apresentado, é evidente que as consequências da apropriação obrigatória desse documento por parte de todos os sujeitos envolvidos no contexto educacional não agregarão contribuições críticas e de superação das injustiças sociais, principalmente depois da drástica mudança da segunda para a terceira versão do documento, pois apresenta retrocessos políticos e pedagógicos. 


\section{REFERÊNCIAS}

ALKIMIN, T. M. Sociolinguística. Parte I. In: MUSSALIM, F.; BENTES, A. C. Introdução à Linguística: domínios e fronteiras, v. 1, 6. ed. São Paulo: Cortez, 2006, p. 21-47.

BETTI, M.; ZULIANI, L. R. Educação física escolar: uma proposta de diretrizes pedagógicas. Revista Mackenzie de Educação Física e Esporte, São Paulo, ano 1, n. 1, p. 73-81, 2002. Disponível em: http://editorarevistas.mackenzie.br/index.php/remef/article/ view/1363/1065. Acesso em: 8 ago. 2018.

BRACHT, V. A constituição das teorias pedagógicas da educação física. Cadernos Cedes, Campinas, ano XIX, n. 48, p. 69-88, ago. 1999a. Disponível em: http://www.scielo.br/pdf/ ccedes/v19n48/v1948a05.pdf. Acesso em: 15 mar. 2018.

BRACHT, V. Educação Física e ciência: cenas de um casamento (in)feliz. Ijuí: Unijuí, 1999b.

BRASIL. Texto constitucional promulgado em 5 de outubro de 1988. Constituição da República Federativa do Brasil. Disponível em: www.planalto.gov.br/ccivil 03/constituicao/constituicao.htm . Acesso em: 11 set. 2018

. Lei $\mathbf{n}^{0} .9 .394$, de 20 de dezembro de 1996. Estabelece as diretrizes e bases da educação nacional. Brasília, DF, 1996. Disponível em: http://portal.mec.gov.br/seesp/arquivos/pdf/lei9394_ldbn1.pdf. Acesso em: 10 set. 2018.

. Secretaria de Educação Fundamental. Parâmetros Curriculares Nacionais, Educação Física, $3^{\circ}$. e $4^{\circ}$. ciclos, v. 7. Brasília: MEC, 1998. Disponível em: http://portal.mec. gov.br/seb/arquivos/pdf/livro07.pdf. Acesso em: 14 jun. 2018.

. Conselho Nacional de Educação; Câmara de Educação Básica. Resolução nº . 7, de 14 de dezembro de 2010. Fixa Diretrizes Curriculares Nacionais para o Ensino Fundamental de 9 (nove) anos. Diário Oficial da União, Brasília, 15 de dezembro de 2010, Seção 1, p. 34. Disponível em: http://portal.mec.gov.br/dmdocuments/rceb007_10.pdf. Acesso em: 13 jun. 2018.

. Ministério da Educação. Base Nacional Comum Curricular, 2a . versão. Brasília: MEC, 2016a.

. Emenda Constitucional $\mathbf{n}^{0} .95$, de 15 de dezembro de 2016. Altera o Ato das Disposições Constitucionais Transitórias, para instituir o Novo Regime Fiscal, e dá outras providências. Brasília, DF, 2016b. Disponível em: http://www.planalto.gov.br/ccivil_03/ Constituicao/Emendas/Emc/emc95.htm 
. Lei $\mathrm{n}^{\mathbf{0}}$. 13.415, de 16 de fevereiro de 2017. Altera as Leis $\mathrm{n}^{\text {os }} 9.394$, de 20 de dezembro de 1996, que estabelece as diretrizes e bases da educação nacional, e 11.494, de 20 de junho 2007, que regulamenta o Fundo de Manutenção e Desenvolvimento da Educação Básica e de Valorização dos Profissionais da Educação, a Consolidação das Leis do Trabalho - CLT, aprovada pelo Decreto-Lei $n^{\circ}$. 5.452, de $1^{\circ}$. de maio de 1943, e o Decreto-Lei $n^{\circ} .236$, de 28 de fevereiro de 1967; revoga a Lei $n^{\circ} .11 .161$, de 5 de agosto de 2005; e institui a Política de Fomento à Implementação de Escolas de Ensino Médio em Tempo Integral. Brasília, DF, 2017. Disponível em: http://www.planalto.gov.br/ccivil_03/_Ato20152018/2017/Lei/L13415.htm. Acesso em: 10 set. 2018.

. Ministério da Educação. Base Nacional Comum Curricular, versão aprovada pelo CNE, novembro de 2017. Disponível em: < http://basenacionalcomum.mec.gov.br/ wp-content/uploads/2018/02/bncc-20dez-site.pdf $>$. Acesso em: $1^{\circ}$. mar. 2018.

CAStellani FILHO, L. Política educacional e Educação Física: polêmicas de nosso tempo. Campinas: Autores Associados, 1998.

DAÓLIO, J. Educação Física e o conceito de cultura (Coleção polêmicas do nosso tempo). Campinas, SP: Autores Associados, 2004.

DARIDO, S. C.; LADEIRA. M. F. T. Educação Física e Linguagem: Algumas considerações iniciais. Motriz, Rio Claro, v. 9, n. 1, p. 31-39, jan./abr. 2003. Disponível em: http:// www.rc.unesp.br/ib/efisica/motriz/09n1/Ladeira.pdf. Acesso em: 10 mar. 2018.

FIORIN, J. L. Introdução à Linguística, 6. ed., 4 reimp. São Paulo: Contexto, 2015.

GRAMORELLI, L. C. O impacto dos PCN na prática dos professores de Educação Física, 2007, 153s. Dissertação (Mestrado em Educação) - Faculdade de Educação, Universidade de São Paulo, São Paulo, 2007. Disponível em: http://www.teses.usp.br/teses/ disponiveis/48/48134/tde-29012008-164956/pt-br.php. Acesso em: 8 abr. 2018.

HALL, S. A centralidade da cultura: notas sobre as revoluções culturais do nosso tempo. Educação e Realidade. Porto Alegre, v. 22, n. 2, p. 15-46, 1997. Disponível em: https:// seer.ufrgs.br/educacaoerealidade/article/view/71361/40514. Acesso em: 10 set. 2018.

HJELMSLEV, L. Prolegômenos a uma teoria da linguagem. São Paulo: Perspectiva, 2006.

JUNDIAÍ. Diretrizes Curriculares da Educação Básica Municipal de Jundiaí SP/ organização CEDUCAMP - Consultoria Educacional e Assessoria Pedagógica Campinas. Jundiaí, SP: Prefeitura Municipal de Jundiaí SP, 2016, 392p. 
KUNZ, E. (Org.). Didática da educação física 1. Ijuí: Ed. Unijuí, 1998.

LIMA VERDE, P. Base Nacional Comum: desconstrução de discursos hegemônicos sobre currículo mínimo. Terceiro Incluído, Goiânia, v. 5, n. 1, p. 78-97, jan.jun. 2015. Disponível em: https:/www.revistas.ufg.br/teri/article/view/36348/18704. Acesso em: 11 set. 2018.

MARSIGLIA, A. C. G.; PINA, L. D.; MACHADO, V. O.; LIMA, M. A Base Nacional Comum Curricular: um novo episódio de esvaziamento da escola no Brasil. Germinal: Marxismo e Educação em Debate, Salvador, v. 9, n. 1, p. 107-121, abr. 2017. Disponível em: https://portalseer.ufba.br/index.php/revistagerminal/article/view/21835/14343. Acesso em: 11 set. 2018.

NEIRA, M. G. Ensino de educação física. São Paulo: Thomson Learning, 2007 (Coleção idéias em ação/ coordenadora Anna Maria Pessoa de Carvalho).

. Terceira versão da BNCC: retrocesso político e pedagógico. In: CONGRESSO BRASILEIRO DE CIÊNCIAS DO ESPORTE /CONGRESSO INTERNACIONAL DE CIÊNCIAS DO ESPORTE, XX/VII, 2017, Goiânia. Anais... Goiânia: [s.n.], 2017, p. 1-6. Disponível em: http://www.gpef.fe.usp.br/teses/marcos_38.pdf. Acesso em: 10 set. 2018.

NEIRA, M. G.; JÚNIOR, M. S. A educação Física na BNCC: procedimentos, concepções e efeitos. Motrivivência, Florianópolis, v. 28, n. 48, p. 188-206, set. 2016. Disponível em: https://periodicos.ufsc.br/index.php/motrivivencia/article/view/2175-8042.2016v28n48p188/32570. Acesso em: 15 ago. 2018.

NEIRA, M. G.; JÚNIOR, W. A.; ALMEIDA, D. F. A primeira e segunda versões da BNCC: construção, intenções e condicionantes. EccoS - Rev. Cient., São Paulo, n. 41, p. 31-44, set./ dez. 2016. Disponível em: http://periodicos.uninove.br/index.php?journal=eccos\&page=arti cle\&op=view\&path $\% 5 \mathrm{~B} \% 5 \mathrm{D}=6807 \&$ path $\% 5 \mathrm{~B} \% 5 \mathrm{D}=3374$. Acesso em: 15 ago. 2018.

NEIRA, M. G.; NUNES, M. L. F. Educação Física, currículo e cultura. São Paulo: Phorte, 2009.

. Linguagem e cultura: subsídios para uma reflexão sobre educação do corpo. Caligrama, v. 3, n. 3, p. 1-16, set./dez. 2007. Disponível em: http://www.revistas.usp.br/caligrama/article/view/66201/68812. Acesso em: 15 ago. 2018.

ORTIZ, Renato. Estudos Culturais. Tempo Social, USP, jun. 2004.

SANTIN, S. Educação física: uma abordagem filosófica da corporeidade. Ijuí: Unijuí, 1987. 
SANTOS, F.; MARCON, D.; TRENTIN, D. T. Inserção da Educação Física na área de Linguagens, Códigos e suas Tecnologias. Motriz, Rio Claro, v. 18, n. 3, p. 571-580, jul./set. 2012. Disponível em: http://www.scielo.br/pdf/motriz/v18n3/a17v18n3.pdf. Acesso em: 7 ago. 2018.

SÃO PAULO. Secretaria Municipal de Educação. Diretoria de Orientação Técnica. Orientações curriculares e proposição de expectativas de aprendizagem para o Ensino Fundamental: ciclo II: Educação Física/ Secretaria Municipal. São Paulo: SME/DOT, 2007, $104 p$.

SÃO PAULO. Secretaria Municipal de Educação. Coordenadoria Pedagógica. Divisão de Ensino Fundamental e Médio. Direitos de aprendizagem dos ciclos interdisciplinar e autoral: Educação Física. São Paulo: SME/COPED, 2016 (Coleção Componentes Curriculares em Diálogos Interdisciplinares a Caminho da Autoria), 80p.

SÃO PAULO. Secretaria Municipal de Educação. Coordenadoria Pedagógica. Currículo da Cidade: Ensino Fundamental: Educação Física. São Paulo: SME/COPED, 2017, 128p.

SÃO PAULO. Secretaria Municipal de Educação. Coordenadoria Pedagógica. Orientações didáticas do currículo da cidade: Educação Física. São Paulo: SME/COPED, 2018, 96p.

SAVIANI, D. Educação escolar, currículo e sociedade: o problema da Base Nacional Comum Curricular. Movimento, v. 3, n. 4, p. 54-84, 2016. Disponível em: http://www.revistamovimento.uff.br/index.php/revistamovimento/article/view/296/301. Acesso em: 22 jun. 2018.

SILVA, T. T. Documentos de identidade: uma introdução às teorias do currículo. Belo Horizonte: Autêntica, 2011.

SOARES, C. L. Educação Física: raízes européias e Brasil, 3. ed. Campinas, SP: Autores Associados, 2004.

SOARES, C. L. et al. Metodologia do ensino de Educação Física. São Paulo: Cortez, 1992.

VAZ, A. C. Educação, corpo e movimento. Curitiba: IESDE, 2010.

VELOZO, E. L. A educação física e as práticas corporais: entre a tradição e a modernidade. In: DAÓLIO, J. Educação física escolar: olhares a partir da cultura. Campinas, SP: Autores Associados, 2010. 
WORTMANN, M. L. C.; VEIGA NETO, A. Estudos culturais da ciência e educação. Belo Horizonte: Autêntica, 2001, 136p.

YOUNG, M. Teoria do currículo: o que é e por que é importante. Cadernos de Pesquisa, São Paulo, v. 44, n. 155, p. 190-202, jan./mar. 2014.

Artigo elaborado a partir da iniciação científica: A Educação Física no campo da Linguagem: as concepções da área e a prática docente na escola - orientador: Me. Fábio Tomio Fuzii, mestre em Ciências da Motricidade Humana pela UNESP/Rio Claro e professor do curso de Educação Física da Universidade Cruzeiro do Sul. Financiamento: PIBIC/ Cruzeirodosul

DADOS DOS AUTORES:

Barbara Cristina Aparecida dos Santos

Graduação em Licenciatura em Educação Física pela Universidade Cruzeiro do Sul. Graduanda em Bacharel em Educação Física pela mesma instituição. Graduanda em Letras pela Universidade Federal de São Paulo. São Paulo/SP - Brasil. barbara.contatouniversitario@hotmail.com

\section{Fábio Toмio FuzII}

Mestre em Ciências da Motricidade pela Universidade Estadual Paulista, Júlio de Mesquita Filho (UNESP/Rio Claro) e graduado em Licenciatura em Educação Física pela mesma Instituição. Professor do curso de Licenciatura e Bacharelado em Educação Física da Universidade Cruzeiro do Sul. São Paulo/SP - Brasil. fabio.fuzii@cruzeirodosul.edu.br

Submetido em: 29-10-2018

Aceito em: 4-4-2019 